This item was submitted to Loughborough's Research Repository by the author.

Items in Figshare are protected by copyright, with all rights reserved, unless otherwise indicated.

\title{
The role of knowledge and understanding in fostering physical literacy
}

\section{PLEASE CITE THE PUBLISHED VERSION}

https://doi.org/10.1123/jtpe.2018-0134

\section{PUBLISHER}

(c) Human Kinetics

\section{VERSION}

AM (Accepted Manuscript)

\section{PUBLISHER STATEMENT}

This work is made available according to the conditions of the Creative Commons Attribution-NonCommercialNoDerivatives 4.0 International (CC BY-NC-ND 4.0) licence. Full details of this licence are available at: https://creativecommons.org/licenses/by-nc-nd/4.0/

\section{LICENCE}

CC BY-NC-ND 4.0

\section{REPOSITORY RECORD}

Cale, Lorraine, and Jo Harris. 2019. "The Role of Knowledge and Understanding in Fostering Physical Literacy”. figshare. https://hdl.handle.net/2134/34757. 
KNOWLEDGE AND UNDERSTANDING IN FOSTERING PHYSICAL LITERACY

Keywords: physical literacy, health, physical education, learning, progression

${ }^{1}$ School of Sport, Exercise and Health Sciences, Loughborough University, UK

*Corresponding Author Email: l.a.cale@lboro.ac.uk

\section{Abstract}

This paper explores the role of knowledge and understanding in fostering physical literacy which is considered fundamental to successful participation in physical activity and to valuing and taking responsibility for engaging in physical activities for life. Firstly, it highlights the place and importance of knowledge and understanding within the broad concept, cognitive domain, and attributes of physical literacy. The type, scope, and progression of knowledge and understanding deemed necessary to foster physical literacy are then explored with attention paid to knowledge of health within the school context in particular. To conclude, the paper outlines selected pedagogical approaches and practical strategies for developing and monitoring such knowledge and understanding. 
KNOWLEDGE AND UNDERSTANDING IN FOSTERING PHYSICAL LITERACY

The Role of Knowledge and Understanding in Fostering Physical Literacy

Given physical literacy is concerned with lifelong participation in physical activity

(Liedl, 2013; Whitehead, 2013) and valuing and taking responsibility for engagement in physical activities for life (Whitehead, 2010a), then arguably fundamental to achieving this is having the required knowledge and understanding of movement and health in terms of how to move, and of why, how, where, and with whom to engage in lifelong physical activity. This paper therefore contributes to the literature in this regard by exploring the role of knowledge and understanding in fostering physical literacy. Firstly, it highlights the place and importance of knowledge and understanding in physical literacy and it then explores the type and scope of knowledge and understanding deemed necessary to foster the concept. Consideration is given to the health knowledge young people should acquire as they progress on their physical literacy journeys through primary and secondary school in particular. The paper concludes by outlining some pedagogical approaches and practical strategies for developing such knowledge and understanding.

\section{Place and Importance of Knowledge and Understanding in Physical Literacy}

Recognition of physical literacy as a holistic concept which goes beyond physical and fundamental movement skills and encompasses knowledge and understanding is now widely acknowledged in the literature (Almond \& Myers, 2017; Edwards, Bryant, Keegan, Morgan, \& Jones, 2017; Ennis, 2015; Liedl, 2013; Lundvall, 2015; Whitehead, 2010a). Knowledge and understanding features explicitly within the International Physical Literacy Association’s (IPLA, 2017) most recent definition of physical literacy which describes the concept as "the motivation, confidence, physical competence, knowledge and understanding to value and take responsibility for engagement in physical activities for life.” Indeed, Ennis (2015) argues that "knowledge is at the heart of physical literacy" (p. 119) with it providing the foundation for knowing what to do and how and when to perform. Meanwhile, Lundvall (2015) warns that 
KNOWLEDGE AND UNDERSTANDING IN FOSTERING PHYSICAL LITERACY

without attention to embodied knowledge, "part of the literacy ambition will be lost” and young people “may not master the keys to lifelong learning through movement” (p. 117). Knowledge and understanding is considered to be a core element within the cognitive domain as well as one of the key attributes of physical literacy (Edwards et al., 2017; Whitehead, 2010a). Following a systematic review of the physical literacy literature, Edwards et al. (2017) identified three core categories within the cognitive domain: (a) knowledge and understanding of activities; (b) knowledge and understanding of healthy and active lifestyles; and (c) the value to take responsibility for physical activity. With respect to knowledge and understanding of activities, a literate sports person (or exerciser) would be knowledgeable about sports/exercise rules, traditions, and values (Kirk, 2013), and in terms of knowledge and understanding of healthy and active lifestyles, they would have a sound awareness of the value of participating in a physically active lifestyle (Whitehead, 2013). More specifically, and in terms of knowledge and understanding as an attribute, “acquiring knowledge in relation to movement and health" is one of the six attributes of physical literacy identified by Whitehead (2010a). She explains how individuals making progress on their physical literacy journey will: ... have the ability to identify and articulate the essential qualities that influence the effectiveness of their own movement performance, and have an understanding of the principles of embodied health with respect to basic aspects such as exercise, sleep and nutrition. (p. 14)

The relationship between the attribute of knowledge and understanding and other attributes of physical literacy is furthermore important to recognize. Indeed, knowledge and understanding is arguably fundamental to achieving the other attributes and the overall concept. For example, having physical competency alone, or any one attribute for that matter, is clearly insufficient to ensure lifelong engagement in physical activity. Knowledge and 
understanding can be enriched by all aspects of participation and characteristically develops

72

73

74 as the attributes of motivation, confidence, physical competence, and fluent interactions grow (Whitehead, 2010b). In turn, knowledge and understanding can positively influence these other attributes in that it will support the appreciation of developing physical competence and the perception of different environments (Whitehead, 2010b) and can enhance motivation and confidence to participate.

Given the above, it is perhaps not surprising that knowledge and understanding is either explicitly or implicitly embedded within the physical education curricula in most countries. To illustrate this, details of the relevant requirements within the National Curriculum in England are summarised later.

\section{Type and Scope of Knowledge and Understanding in Physical Literacy} Just as physical literacy is a holistic concept, physical literacy knowledge and understanding should equally be seen holistically. As already noted, knowledge and understanding within the cognitive domain and as an attribute have different components, with two constituents to the latter. The first is concerned with grasping the essential principles of movement and performance and the other with health and fitness (Whitehead, 2010b). Whitehead argues that if lifelong involvement in physical activity is to be achieved then it is clearly important for individuals to take some responsibility for both.

The first constituent expects individuals who are making progress on their physical literacy journey to appreciate the basic components of movement and be able to evaluate their own performance and that of others, using appropriate vocabulary and observing movement (Whitehead, 2010b). With regards the constituent of health and fitness, Whitehead claims it is essential that individuals adopt an objective view of themselves in deciding how best to manage aspects of life suggesting "it would be unacceptable for the concept to omit the care, attention and respect individuals should show to their embodied dimension” (p. 66). 
KNOWLEDGE AND UNDERSTANDING IN FOSTERING PHYSICAL LITERACY

96

97

98

99

100

101

102

103

104

105

106

107

108

109

110

111

112

113

114

115

116

117

118

119

120

Such knowledge and understanding understandably then typically features within the physical education curricula in schools. In England, for example, and with respect to knowledge of movement, successive versions of the National Curriculum for Physical Education include the aspects of developing knowledge and understanding of ways to promote improvement through evaluation of one’s own and others' performances and taking steps or making suggestions for improvement. Indeed, these elements feature explicitly in the current National Curriculum (Department of Education, 2013a, 2013b) for pupils from 7 years of age upwards. The programmes of study state that for 7-11 year olds (key stage 2), pupils "should develop an understanding of how to improve in different physical activities and sports and learn how to evaluate and recognise their own success," and be taught to "compare their performances with previous ones and demonstrate improvement to achieve their personal best” (2013a, p. 2). For 11-14 year olds (key stage 3), pupils “should understand what makes a performance effective and how to apply these principles to their own and others' work,” and be taught to "develop their technique and improve their performance...," as well as "analyse their performances compared to previous ones and demonstrate improvement to achieve their personal best” (2013b, p. 2). For 14-16 year olds (key stage 4), pupils should similarly be taught to "develop their technique and improve their performance (in other sports or other physical activities),” plus “evaluate their performances compared to previous ones and demonstrate improvement across a range of physical activities to achieve their personal best” (2013b, p. 3).

As noted by Whitehead (2010b), the above clearly involve firstly being able to diagnose what is making a movement or movement pattern more or less effective and then understanding how to improve and develop it. This should encompass experiences within a wide range of activity settings and by involving participants in observation, analysis, description, and evaluation (Whitehead, 2010a, 2010b). 
KNOWLEDGE AND UNDERSTANDING IN FOSTERING PHYSICAL LITERACY

121

122

123

124

125

126

127

128

129

130

131

132

133

134

135

136

137

138

139

140

141

142

143

144

145

With regards to knowledge of health, and again drawing on the National Curriculum in England, ensuring that all pupils "are physically active for sustained periods of time" (Department of Education, 2013a, 2013b, p. 1) and “lead healthy, active lives” (p. 1) represent two of the main aims of the subject across the age range. Interestingly though, and despite these aims, reference to knowledge and understanding in relation to health in the programmes of study is somewhat limited and more implicit. For example, pupils aged 11-14 years (key stage 3) should "develop the confidence and interest to get involved in exercise, sports, and activities out of school” and in later life and "understand and apply the long-term benefits of physical activity" (2013b, p. 2), whilst 14-16 year olds (key stage 4) should "get involved in a range of activities that develops personal fitness and promotes an active, healthy lifestyle” (2013b, p. 3).

To achieve the above aims and notably to lead a healthy active life, a sound and broad knowledge and understanding in the area is clearly required. Further, it is contended that this needs to extend beyond the rather limited knowledge and understanding requirements implied in the National Curriculum and the "basic aspects" of exercise, sleep, and nutrition identified by Whitehead (2010a, p. 14). At the same time, it is fully accepted that physical literacy knowledge and understanding does not demand a grasp of technical biomechanical and medical scientific concepts (Whitehead, 2007, 2010b).

On this issue, Armour and Harris (2013) claim that much of the international physical education community is unclear about the precise nature of appropriate health knowledge to be covered in the subject. Given the different views expressed in the literature, this claim would seem to be founded suggesting a need to identify the health knowledge and experiences required to be able to successfully engage in physical activities for life. For this reason, alongside well reported concerns over physical education teachers’ limited health knowledge and their delivery of health in the curriculum generally (Alfrey, Cale, \& Webb, 
KNOWLEDGE AND UNDERSTANDING IN FOSTERING PHYSICAL LITERACY

146 2012; Cale \& Harris, 2013; Castelli \& Williams, 2007; Fardy, Azzollini, \& Herman, 2004;

147 Harris, 2010; Harris \& Leggett, 2015; Hastie, 2017; Keating et al., 2009; Kulinna,

148 McCaughtry, Martin, Cothran, \& Faust, 2008; McKenzie, 2007; Puhse et al., 2011; Trost,

149 2006), the main focus of the discussion from hereon will centre on knowledge relating to

150 health. In 2000, and in recognition of the above, a working group comprising representatives

151 of national physical education, sport, and health organisations in England was formed in an

152 attempt to achieve consensus on health-related learning within the subject, a key output of

153 which was the publication of national guidance including health-related outcomes for

154 children aged 5 to 16 years (Harris, 2000). These outcomes are detailed fully elsewhere (see

155 Harris, 2000; Harris \& Cale, 2018) and include a number of cognitive (knowledge and

156 understanding), as well as affective and behavioural outcomes. To illustrate the scope in

157 learning they are presented in four categories: safety issues, exercise effects, health benefits,

158 and activity promotion, representing the key areas of learning considered necessary to engage

159 in lifelong physical activity. In summary, for individuals to successfully engage in physical

160 activity for life, it is important that they know and understand (a) how to take part in physical

161 activity safely and effectively (safety issues), (b) the body’s response to participating in

162 physical activity (exercise effects), (c) the reasons for participating in physical activity

163 (health benefits), and (d) what physical activity to take part in, where and how (activity

164 promotion).

165 In addition, and in recognition of physical literacy as a journey through which

166 individuals develop throughout their lifespan from cradle to grave (Edwards et al., 2017),

167 gradually acquiring wider and deeper knowledge and understanding (Whitehead, 2010b), the

168 learning outcomes (Harris, 2000; Harris \& Cale, 2018) are presented by age group or key

169 stage (KS): 5-7 years (KS1), 7-11 years (KS2), 11-14 years (KS3), and 14-16 years (KS4).

170 These represent the middle stages of Whitehead's (2013) age-related stages which individual 
KNOWLEDGE AND UNDERSTANDING IN FOSTERING PHYSICAL LITERACY

171 journeys pass through and which span from preschool through to the older adult years. Thus,

172 whilst it is acknowledged that individuals develop at different rates in light of their different

173 abilities, contexts (social cultural and geographical), and experiences, the outcomes broadly

174 illustrate how individuals' learning about health is expected to progress. Example knowledge

175 and understanding outcomes for each of the age ranges and for each category are shown

176 below. Although these were initially produced to support teachers in developing pupils'

177 knowledge and understanding, they can and should equally be reinforced by parents and

178 others, as appropriate. Learning outcomes associated with each age group are presented in

179 Table 1. Table 1 is adapted from the initial work of Harris (2000).

Place Table 1 Here

With respect to the above knowledge, research has revealed that the more instrumental outcomes, for example, those relating to safety issues (e.g., safe practice and warming up and cooling down) and to exercise effects (i.e., the short term effects of exercise on the body) are more frequently addressed by physical education teachers than those associated with health benefits and activity promotion (Harris, 2010). Yet, it is evidently the latter outcomes which are mostly closely linked to valuing and engaging in physical activities for life. Alfrey and Gard (2014) similarly acknowledge how the profession is depicted as clearly focussed on the dualistic and instrumental understandings of health and the body, and consequently how in turn this leads to many teachers focussing on and applying the same narrow instrumental outcomes in their delivery. The need for a broader approach which pays more attention to

191 health and activity promoting outcomes is therefore recommended (Harris, 2000; Harris \&

192 Cale, 2018) and it seems is needed if physical literacy is to be truly fostered. In addition, recent calls have been made for approaches which adopt a socially-critical perspective to health knowledge and information (Burrows, Wright, \& McCormack, 2009; Haerens, Kirk,

195 Cardon, \& De Bourdeaudhuij, 2011). Example knowledge and understanding outcomes 
KNOWLEDGE AND UNDERSTANDING IN FOSTERING PHYSICAL LITERACY

196

197

198

199

200

201

202

203

204

205

206

207

208

209

210

211

212

213

214

215

216

217

218

219

220

221

related to health benefits and activity promotion illustrating how they progress with school age are shown in Table 2.

Place Table 2 Here

\section{Fostering Knowledge and Understanding in Physical Literacy}

According to Almond (2010, p. 124), “physical literacy and its associated

characteristics (or attributes) have no value unless they can be applied to and influence common practice.” In fostering knowledge and understanding of physical literacy, the content and its delivery are clearly key and need to be appropriate to ensure that all

individuals have the opportunity to acquire knowledge and understanding both of movement and of health, and of the relationship between physical activity and health (Murdoch \& Whitehead, 2010).

In developing knowledge and understanding, there are some general principles which should be subscribed to. Physical literacy is, by definition, concerned with the physical and as such the concept and attributes should be developed within and through the physical, and through a range of activities, with knowledge and understanding of movement and health being no exception in this regard. Developing the former through the physical is common and clearly common sense, but evidence suggests this is not always the case for the latter. Despite it being found to be relatively ineffective (Cale \& Harris, 2006), classroom-based delivery of health-related theoretical concepts and information in schools is often reported (Cale, 2017; Cale \& Harris, 2006). A further limitation with classroom-based delivery is that it is sedentary, thereby detracting from potential active time, and with the focus tending to be restricted to information transmission rather than developing knowledge via a combination of understanding, experiencing, decision making and evaluating (Cale, 2017; Cale \& Harris, 2013). On the other hand, learning about health through active participation in purposeful physical activity is not only consistent with the physical context of the subject and with messages relating health benefits to frequent physical activity, but it helps to increase activity 
KNOWLEDGE AND UNDERSTANDING IN FOSTERING PHYSICAL LITERACY

222 levels and contribute to young people’s overall physical activity (Harris, 2000; Harris \& Cale,

223

224

225

2018). As highlighted later, and if taught effectively, it also potentially allows both

knowledge and understanding of movement and of health to be developed simultaneously, whilst developing other core attributes of physical literacy as well.

Other principles which are fundamental to developing knowledge and understanding, and arguably to all good teaching, are the inclusion and empowerment of all pupils, and their subsequent shift with enhanced knowledge and understanding from dependence on the teacher to independence. In considering approaches to physical literacy development, Almond and Myers (2017) argue we need to consider the gradual process of emerging empowerment, independence, and agency as central to how we nurture young people's learning paths. The provision of positive, relevant, meaningful, and rewarding physical activity learning experiences is central to facilitating this process and fostering empowered and independent individuals capable of making informed lifestyle choices. On this, Elbourn and James (2013) identify three key elements important to the empowerment of young people with respect to healthy active lifestyles: (a) appropriate content, (b) appropriate context, and (c) effective pedagogy. Appropriate content is that which is deemed to be safe, progressive, relevant, well informed, inclusive, and fun, whilst appropriate context relates to the range of activities through which learning can be promoted such as a variety of games, dance, gymnastic, or fitness or exercise activities. Effective pedagogy is that which, amongst other things, is "personalised, enabling, and collaborative, and which facilitates informed decision making and uses active learning strategies” (Elbourn \& James, 2013, p. 2).

Different organisational approaches to developing knowledge and understanding of health are available which have been the subject of much debate and critique over the years (Cale \& Harris, 2005, 2009, 2013; Murdoch \& Whitehead, 2010). Health-related learning outcomes can be taught within the curriculum, within and beyond physical education. If 
KNOWLEDGE AND UNDERSTANDING IN FOSTERING PHYSICAL LITERACY

247 within physical education, learning can be permeated through the core traditional activities

248 such as athletics, dance, games, gymnastics, outdoor education and swimming, taught

249 discretely in separate health-related units of work, or delivered via a combination of these

250 approaches. There are merits as well as drawbacks with each. To summarise, the strengths

251 of a permeation approach are that health knowledge and understanding can be seen as related

252 and integral to all physical education experiences and thus pupils learn that all physical activities can contribute towards health, thus endorsing the close relationship between health issues and participation (Harris, 2000; Murdoch \& Whitehead, 2010). Via a permeated approach, a skilled teacher may also be able to effectively develop both aspects of physical literacy knowledge and understanding, that is, of movement and of health. However, a key limitation levelled at this approach is that integrating the health-related learning through the teaching of the core traditional activities may result in it becoming lost or marginalised and it taking second place to other learning such as skill development or tactical understanding (Cale \& Harris 2005; Harris \& Cale, 2018). The discrete approach avoids this issue and ensures health is not overlooked, but a drawback in teaching it in isolation through separate units may imply that it does not relate closely to other learning and elements of physical education, physical literacy, and other curriculum subjects (Harris \& Cale, 2018; Murdoch \& Whitehead, 2010). On balance, a combined approach is advocated in that it builds on the strengths of each, helps to reinforce and ensure the consistency and coherence of learning, and provides a realistic opportunity to more adequately address the required knowledge base

267 (Cale \& Harris, 2009). It also allows links to be made to other physical education and physical activity experiences and health behaviours and subjects (Cale \& Harris, 2005, 2009). For example, it is recommended that links are made with learning in related subjects such as personal, social and health education science (PSHE), and food technology, plus with extra-

271 curricular and/or community activity experiences where appropriate. Furthermore, 
KNOWLEDGE AND UNDERSTANDING IN FOSTERING PHYSICAL LITERACY

information and advice about such opportunities can be communicated to pupils as well as their families in a variety of ways (e.g., via newsletters, visual displays, parent email, parent consultations, assemblies, school web site; Harris \& Cale, 2018). This is in fact akin to a whole school approach to health which is growing in popularity and increasingly being advocated within and beyond the United Kingdom (All-Party Commission on Physical Activity, 2014; Blanchard, Shilton, \& Bull, 2013; Cale, Harris, \& Duncombe, 2016; McMullen, Ní Chróinín, Tammelin, Pogorzelska, \& van der Mars, 2015).

Concerns over the delivery of health were alluded to earlier. Indeed, alongside a lack of clarity about the nature of appropriate health knowledge to cover, it is suggested teachers also lack appropriate PE-for-health pedagogies (Armour \& Harris, 2013; i.e., strategies for delivering health). Consequently, a number of researchers have called for more and alternative methods, strategies, or models to effectively teach health-related knowledge (Armour \& Harris, 2013; Haerens et al., 2011; Hastie, Chen, \& Guarino, 2017; Hodges, Kulinna, Lee, \& Kwon, 2017). Indeed, critical of prevailing approaches, Armour and Harris (2013) argue there has been surprisingly little new knowledge on health pedagogies that could support teachers in re-contextualizing health knowledge to meet the diverse learning needs of pupils and therefore call for a renewed focus on developing PE-for-health pedagogies.

In recognition of this, there have been some recent encouraging pedagogical developments which are considered to have potential, two notable ones of which are outlined below and include the Health-Based Physical Education Model (HBPE; Haerens et al., 2011) and the Physically Active Lifestyle (PAL) Principles (Harris, Cale, Casey, Tyne, \& Samaria, 2016). These have typically built on and been informed by the lessons learnt from previous health-related approaches originating primarily from the United States and Australia (Haerens et al., 2011). In addition, other relevant developments which have shown promise recently 
KNOWLEDGE AND UNDERSTANDING IN FOSTERING PHYSICAL LITERACY

include Knowledge in Action Lesson Segments (Hodges et al., 2017) and the Project-Based Learning Model (Hastie, Chen, \& Guarino, 2017).

The HBPE model is considered to be highly compatible with the aims of physical literacy, having as its central theme "pupils valuing a physically active life, so that they learn to value and practice appropriate physical activities that enhance health and wellbeing for the rest of their lives” (Haerens et al., 2011, p. 321). Since 2011, the model has undergone an extensive period and comprehensive process of development with teachers, teacher educators, and pupils resulting in some positive outcomes for teachers and pupils (Bowler, Sammon, Casey, Haerens, \& Kirk, 2012; Bowler et al., 2015). The model draws on self-determination theory, the social ecological model, and theories of behaviour change and identifies four goals for HBPE including the characteristics of habitual, motivated, informed, and critical movers. The affective domain is prominent in planning for learning emphasising the importance of valuing a physically active life as a sustainable long-term process, knowledge as a significant component, and of focussing beyond the individual to the wider community. In this respect, and whilst intended to be used flexibly to inform learning outcomes and the delivery of health knowledge and content, the model proposes that: (a) pupils’ psychological needs for autonomy, competence, and relatedness should be prioritised; (b) teachers should promote physical activity within and beyond lessons, maximising lesson opportunities and interacting with parents and community bodies; (c) lessons should include physical activity learning opportunities, such as current guidelines, age-related statistics, local opportunities, and safe/effective practice; and (d) pupils should understand physical activity barriers, potential strategies to overcome these and become movement activists for their peers/family (Bowler et al., 2012).

Another pedagogical approach to promoting knowledge and understanding of health is the adoption of PAL Principles (Harris et al., 2016). These principles emanated from a 
KNOWLEDGE AND UNDERSTANDING IN FOSTERING PHYSICAL LITERACY

322 small-scale action-based study with teachers and trainee teachers which aimed to develop and

323 trial a principle-based approach to promoting active lifestyles which could inform policies,

324 delivery, and resources suitable for use by teachers and schools (Cale, Harris, \& Hooper,

325 2017). Informed by the literature and underpinned by social cognitive theory and the social

326 ecological model, participants were involved in developing, trialling, evaluating, and

327 agreeing on a number of whole school and physical education-specific PAL principles, some

328 of which explicitly focus on the development of knowledge and understanding in this area.

329 Key considerations in the design and implementation of the principles were in ensuring their

330 flexibility, simplicity, accessibility, and sustainability. Thus, there are no rigid rules and no

331 prescriptive or structured programme for teachers to follow in incorporating them and

332 minimal training and no or few resources are needed to do so. The findings from the study

333 were encouraging revealing changes in teachers' pedagogies to increase activity levels and

334 positive responses from pupils (Cale et al., 2017).

335 Examples of whole school PAL principles which require and involve the development

336 of appropriate knowledge and understanding include (Harris et al., 2016):

- Include the physical activity for health guidelines for children in the teaching of PSHE (alongside other health guidelines) as well as in physical education.

- Discuss the promotion of active lifestyles, including marketing the 'one hour a day' physical activity guideline, with all staff, governors, pupils and parents/carers.

- Promote active travel to school (cycling, walking, scooting)... (p. 52)

342 Likewise, relevant examples of physical education PAL principles include (Harris et al., 343 2016):

344 - Teach pupils about the broad range of benefits (physical, psychological and social) of 345 a healthy, active lifestyle, including the role of physical activity in healthy weight management. 
KNOWLEDGE AND UNDERSTANDING IN FOSTERING PHYSICAL LITERACY

347

348

349

350

351

352

353

354

355

356

357

358

359

360

361

362

363

364

365

366

367
- Include assessment of learning and progress in active ways (e.g. show me...; demonstrate...; shadow...).

- Routinely inform pupils where they can be active within 3-5 miles of the school radius (in every unit of work and via the school's intranet/library).

- Teach pupils how active they should be, involve them in monitoring their activity levels so they become aware of how active they are, and inform them of multiple ways of increasing their activity levels.

- Identify low active pupils and offer them (and their parents/carers) support/guidance/information and targeted/bespoke activity sessions. (p. 52) In developing knowledge and understanding, not only is identifying appropriate knowledge and approaches for delivering it important, but so too is monitoring the acquisition of this knowledge to establish the progress being made. Knowledge and understanding of health can be assessed via written, verbal, and active responses to focussed questions and tasks as well as via teacher observation (Cale \& Harris, 2009). Peer- and selfassessment of health-related learning are also very appropriate as they directly involve pupils in making judgements and decisions about their own and others’ learning (Harris \& Cale, 2018). Furthermore, just as knowledge should be developed through the physical it is recommended that, whenever possible, assessment of knowledge should be through the physical for the same reasons. Active assessment methods represent one of the physical education PAL principles and can involve physical responses to focussed questions and practical tasks and activities which require demonstration and application of knowledge and understanding. Various assessment methods, taken and/or modified from elsewhere (e.g., Cale \& Harris, 2009; Harris \& Cale, 2018) are presented below. Whilst these assessments can be applied to different ages and abilities, it is anticipated that they be adapted, as appropriate, and that the nature and depth of expected response will similarly be different. 
KNOWLEDGE AND UNDERSTANDING IN FOSTERING PHYSICAL LITERACY

372 Focused questions/activities (pupil-teacher or pupils-pupil) include: (a) Show me and name

373 which muscles are working hard when you run/jump/throw; (b) Why is it important to stretch

374 muscles after you have worked them hard?; (c) How much (and what type of) activity should

375 young people do?; (d) Explain to a partner why physical activity is good for your health; and

376 (e) What are some of the main reasons why young people are not active? Practical tasks

377 include: (a) Show me a stretch for the muscles in..... the back of your leg/hamstring/calf, the

378 front of your thigh/quadriceps, chest/pectorals, etc.; (b) Perform an exercise which will

379 strengthen your.... tummy/stomach/abdominal muscles, leg/thigh muscles/quadriceps,

380 arms/triceps, etc.; (c) With a partner, plan and perform a warm up which includes mobilising

381 and pulse raising activities followed by stretches of the main muscles; (d) Observe another

382 group's cool-down for sprinting and decide how effective it is (in reducing heart and

383 breathing rates and stretching out the main muscles that were worked hard); and (e) Prepare

384 some advice for a member of your family who wishes to become more active. Identify and

385 include 10 top tips/pieces of information you think will help them to take part safely and

386 achieve their goal (of enjoying a physically active lifestyle).

\section{Conclusion}

Fundamental to physical literacy and to participating, valuing, and taking

389

390

391

392

393

394

395

396 responsibility for engaging in physical activities for life is knowledge and understanding of movement and health, which is either explicitly or implicitly embedded within the physical education curricula in most countries. To foster the above, and notably to lead a healthy active life, a sound, broad, and holistic knowledge and understanding is clearly required. With reference to health specifically, and in an attempt to achieve consensus on and illustrate the scope in health-related learning, health-related outcomes for children have been published covering four key categories: safety issues, exercise effects, health benefits, and activity promotion. The latter outcomes relating to health and promoting activity are, however, 
KNOWLEDGE AND UNDERSTANDING IN FOSTERING PHYSICAL LITERACY

397

398

399

400

401

402

403

404

405

406

407

408

409

410

411

412

413

414 identifying appropriate knowledge and approaches for delivering health important, but so too

415 is monitoring the acquisition of this knowledge to establish the progress being made. This

416 can be done in various ways and it is recommended that, where possible, assessment should

417 be through the physical (i.e., active, and via a range of practical strategies and methods). 
KNOWLEDGE AND UNDERSTANDING IN FOSTERING PHYSICAL LITERACY

419

420

421

422

423

424

425

426

427

428

429

430

431

432

433

434

435

436

437

438

439

440

441

442

443

\section{References}

Alfrey, L., Cale, L., \& Webb, L. (2012). Physical education teachers' continuing professional development in health-related exercise. Physical Education and Sport Pedagogy, 17, 477-491.

Alfrey, L., \& Gard, M. (2014). A crack where the light gets in: a study of health and physical education teachers’ perspectives on fitness testing as a context for learning about health. Asia-Pacific Journal of Health, Sport and Physical Education, 5(1), 3-18.

Almond, L. (2010). Physical literacy and the older adult population. In M. Whitehead (Ed.), Physical literacy: Throughout the lifecourse (pp. 116-129). London, UK: Routledge.

Almond, L., \& Myers, L. (2017). Physical literacy and the primacy of movement. Physical Education Matters, 12(1), 19-21.

All-Party Commission on Physical Activity. (2014). Tackling physical inactivity - A coordinated approach. Retrieved from http://activitycommission.com/

Armour K.M., \& Harris, J. (2013). Making the case for developing new PE-for-health pedagogies. Quest, 65, 201-219.

Blanchard C., Shilton, T., \& Bull, F. (2013). Global Advocacy for Physical Activity (GAPA): Global leadership towards a raised profile. Global Health Promotion, 20, 113-121.

Bowler, M., Sammon, P., Casey, A., Haerens, L., \& Kirk, D. (2012, September). Validating the health-based physical education pedagogical model: Defining teacher and student benchmarks. Paper presented at the British Educational Research Association Annual Conference, University of Manchester, UK.

Bowler, M., Sammon, P., Kirk, D., Haerens, L., Cale, L., \& Casey, A. (2015, July). Developing a 'prototype' health-based physical education pedagogical model. Paper presented at the International Association for Physical Education in Higher Education Annual Conference, Universidad Europea, Madrid, Spain. 
KNOWLEDGE AND UNDERSTANDING IN FOSTERING PHYSICAL LITERACY

444 Burrows, L., Wright, J., \& McCormack, J. (2009). Dosing up on food and physical activity: New Zealand children’s ideas about 'health.' Health Education Journal, 68, 157-169.

446

447

448

449

450

451

452

453

454

455

456

457

458

459

460

461

462

463

464

465

466

467

Cale, L. (2017). Teaching about Healthy Active Lifestyles. In C.D. Ennis (Ed.), Routledge handbook of physical education pedagogies (pp. 399-411). Oxon, UK: Routledge.

Cale, L., \& Harris, J. (Eds.). (2005). Exercise and young people. Issues, implications and initiatives. Basingstoke, UK: Palgrave Macmillan.

Cale, L., \& Harris, J. (2006). School based physical activity interventions - Effectiveness, trends, issues, implications and recommendations for practice. Sport, Education and Society, 11, 401-420.

Cale, L., \& Harris, J. (2009). Getting the buggers fit ( $2^{\text {nd }}$ ed.). London, UK: Continuum.

Cale, L., \& Harris, J. (2013). Physical education and health: Considerations and issues. In S. Capel \& M. Whitehead (Eds.), Debates in physical education (pp. 74-88). Oxon, UK: Routledge.

Cale, L., Harris, J., \& Duncombe, R. (2016). Promoting physical activity in secondary schools. Growing expectations: Same old issues. European Physical Education Review, 22, 526-544.

Cale, L., Harris. J., \& Hooper, O. (2017, January). The Promoting Active Lifestyles project. Paper presented at the $30^{\text {th }}$ Australian Council for Health, Physical Education and Recreation (ACHPER) International Conference, University of Canberra, Australia.

Castelli, D., \& Williams, L. (2007). Health-related fitness and physical education teachers' content knowledge. Journal of Teaching in Physical Education, 26, 3-19.

Department for Education. (2013a). Programmes of study for physical education - Key stages 1 and 2. Retrieved from https://www.gov.uk/government/publications/nationalcurriculum-in-england-physical-education-programmes-of-study 
KNOWLEDGE AND UNDERSTANDING IN FOSTERING PHYSICAL LITERACY

468

469

470

471

472

473

474

475

476

477

478

479

480

481

482

483

484

485

486

487

488

489

490

Department for Education. (2013b). Programmes of study for physical education - Key stages 3 and 4. Retrieved from https://www.gov.uk/government/publications/nationalcurriculum-in-england-physical-education-programmes-of-study

Edwards, L.C., Bryant, A.S., Keegan, R.J., Morgan, K., \& Jones, A.M. (2017). Definitions, foundations and associations of physical literacy: A systematic review. Sports Medicine, 47, 113-126.

Elbourn, J., \& James, A. (2013). Fitness room activities for secondary schools. A guide to promoting effective learning about healthy active lifestyles. Leeds, UK: Coachwise.

Ennis, C.D. (2015). Knowledge, transfer and innovation in physical literacy curricula. Journal of Sport and Health Science, 4, 119-124.

Fardy, P.S., Azzollini, A., \& Herman, A. (2004). Health-based physical education in urban high schools: The PATH program. Journal of Teaching in Physical Education, 23, $359-371$.

Haerens, L., Kirk, D., Cardon, G., \& De Bourdeaudhuij, I. (2011). Toward the development of a pedagogical model for health-based physical education. Quest, 63, 321-338.

Harris, J. (2000). Health-related exercise in the national curriculum. Leeds, UK: Human Kinetics.

Harris, J. (2010). Health-related physical education. In R. Bailey (Ed.), Physical education for learning: A guide for secondary schools (pp. 26-36). London, UK: Continuum.

Harris, J., \& Cale, L. (2018). Promoting active lifestyles in schools. Leeds, UK: Human Kinetics.

Harris, J., Cale, L., Casey, A., Tyne, A., \& Samaria, B. (2016). Promoting active lifestyles in schools. The PAL project. Physical Education Matters, 11(3), 52-53. 
KNOWLEDGE AND UNDERSTANDING IN FOSTERING PHYSICAL LITERACY

491 Harris, J., \& Leggett, G. (2015). Influences on the expression of health within physical

492

493

494

495

496

497

498

499

500

501

502

503

504

505

506

507

508

509

510

511

512

513

514 education curricula in secondary schools in England and Wales. Sport Education and Society, 20, 908-923.

Hastie, P. (2017). Revisiting the National Physical Education Content Standards: What do we really know about our achievement of the physically educated/literate person? Journal of Teaching in Physical Education, 36, 3-19.

Hastie, P.A., Chen, S., \& Guarino, A.J. (2017). Health-related fitness knowledge development though project-based learning. Journal of Teaching in Physical Education, 36, 119-125.

Hodges, M., Kulinna, P.M., Lee, C., \& Kwon, J.Y. (2017). Professional development and teacher perceptions of experiences teaching health-related fitness knowledge. Journal of Teaching in Physical Education, 36, 32-39.

International Physical Literacy Association (IPLA). (2017). Retrieved from https://www.physical-literacy.org.uk/

Keating, X.D. Harrison, L., Chen, L., Xiang, P., Lambdin, D., Dauenhauer, . . Pinero, J.C. (2009). An analysis of research on student health-related fitness knowledge in K-16 physical education programs. Journal of Teaching in Physical Education, 28, 333-349.

Kirk, D. (2013). Educational value and models-based practice in physical education. Educational Philosophy Theory, 45, 973-986.

Kulinna, P.H., McCaughtry, N., Martin, J.J., Cothran, D., \& Faust, R. (2008). The influence of professional development on teachers' psychosocial perceptions of teaching a healthrelated physical education curriculum. Journal of Teaching in Physical Education, 27, 292307.

Liedl, R. (2013). A holistic approach to supporting physical literacy. Physical and Health Education Journal, 79(2), 19. 
KNOWLEDGE AND UNDERSTANDING IN FOSTERING PHYSICAL LITERACY

515 Lundvall, S. (2015). Physical literacy in the field of physical education - A challenge and a possibility. Journal of Sport and Health Sciences, 4, 113-118.

517

518

519

520

521

522

523

524

525

526

527

528

529

530

531

532

533

534

535

536

537

538

539

McKenzie, T.L. (2007). The preparation of physical educators: A public health perspective. Quest, 59, 346-357.

McMullen, J., Ní Chróinín, D., Tammelin, T., Pogorzelska, M., \& van der Mars, H. (2015). International approaches to whole-of-school physical activity promotion. Quest, 67, 384-399.

Murdoch, E., \& Whitehead, M. (2010). Physical literacy, fostering the attributes and curriculum planning. In M. Whitehead (Ed.), Physical literacy: Throughout the lifecourse (pp. 175-188). London, UK: Routledge.

Puhse, U., Barker, D., Brettschneider, W.D., Feldmeth, A.K., Gerlach, E., McCuaig, L., . . Gerber, M. (2011). International approaches to health-oriented physical education: Local health debates and differing conceptions of health. International Journal of Physical Education, 3, 2-15.

Trost, S. (2006). Public health and physical education. In D. Kirk, D. Macdonald, \& M. O’Sullivan (Eds.), The handbook of physical education (pp. 63-187). London, UK: Sage.

Whitehead, M. (2007). Physical literacy: Philosophical considerations in relation to developing a sense of self, universality and propositional knowledge. Sport, Ethics and Philosophy, 1, 281-298.

Whitehead, M. (2010a). The concept of physical literacy. In M. Whitehead (Ed.), Physical literacy: Throughout the lifecourse (pp. 10-20). London, UK: Routledge.

Whitehead, M. (2010b). Physical literacy, the sense of self, relationships with others and the place of knowledge and understanding in the concept. In M. Whitehead (Ed.), Physical literacy: Throughout the lifecourse (pp. 56-67). London, UK: Routledge. 
KNOWLEDGE AND UNDERSTANDING IN FOSTERING PHYSICAL LITERACY

540 Whitehead, M. (2013). The value of physical literacy. ICSSPE Journal of Sport Science and Physical Education, 65, 42-43. 
KNOWLEDGE AND UNDERSTANDING IN FOSTERING PHYSICAL LITERACY

542

543

544

545

546

547

548

549

550

551

552

553

554

555

556

557

558

559

560

561

562

563

564

565

566

Table 1

Learning Outcomes Associated with National Curriclulum Key Stages

Pupils who are 5-7 years can:

- explain that activity starts with a gentle warm up and finishes with a calming cool down (safety issues)

- recognise and describe the effects of exercise, including changes to: breathing (e.g. becomes faster and deeper), heart rate (e.g. heart pumps more quickly), temperature (e.g. feel hotter), appearance (e.g. look hotter), feelings (e.g. feeling good, more energetic, tired) (exercise effects)

- explain that regular activity improves health by making you feel good (e.g. happy, pleased, content) and helping body parts (e.g. bones and muscles) to grow, develop and work well (health benefits)

- identify when, where and how they can be active at school (in and out of lessons) (activity promotion).

Pupils who are 7-11 years can:

- explain the need for safety rules and practices (e.g. adopting good posture, changing clothes and having a wash after energetic activity, wearing suitable footwear, following rules, safe lifting) (safety issues)

- explain and feel the short-term effects of exercise (e.g. breathing increases in order to provide more oxygen to the working muscles, the heart rate increases to pump more oxygen to the working muscles, body temperature increases because working muscles produce energy as heat) (exercise effects)

- explain that exercise strengthens bones and muscles (including the heart) and helps to keep joints flexible (health benefits) 
KNOWLEDGE AND UNDERSTANDING IN FOSTERING PHYSICAL LITERACY

567

568

569

570

571

572

573

574

575

576

577

578

579

580

581

582

583

584

585

586

587

588

589

590

591

- identify when, where and how they can be active in school and outside... and explain that individuals have different feelings about the types and amounts of activity that they choose to do (activity promotion).

Pupils who are 11-14 years can:

- explain the value of preparing for and recovering from activity and the possible consequences of not doing so, and the purpose of each component of a warm up and cool down (i.e. mobility exercises, whole body activities, static stretches) for general activity and for a specific activity (safety issues)

- explain a range of short-term effects of exercise on the cardiovascular system (e.g. changes in: breathing and heart rate, temperature, appearance, feelings, recovery rate) and musculo-skeletal system (e.g. increases in muscular strength and endurance and flexibility, improved muscle tone and posture, enhanced functional capacity) (exercise effects)

- explain a range of long-term benefits of exercise on physical health (e.g. reduced risk of chronic disease (e.g. heart disease), reduced risk of bone disease (e.g. osteoporosis), reduced risk of some health conditions (e.g. obesity, back pain), improved management of some health conditions (e.g. asthma, diabetes, arthritis) (health benefits)

- know ways of incorporating exercise into their lifestyles (e.g. walking or cycling to school or to meet friends, helping around the home/garden) (activity promotion).

Pupils who are 14-16 years can:

- recognise and manage risk and apply safe exercise principles and procedures (e.g. not exercising when unwell or injured, avoiding prolonged high impact exercise, administering first aid including resuscitation techniques, avoiding excessive exercise) (safety issues) 
- explain that frequent and appropriate activity enhances the physical, social and psychological well-being of all individuals including the young and old, able-bodied and disabled, and those with health conditions (e.g. asthma, depression) and chronic disease (e.g. arthritis) (health benefits)

- explain that training programmes develop both health-related components (cardiovascular fitness, muscular strength and endurance, flexibility, body composition, composure, decision-making) and skill-related components of physical and mental fitness (agility, balance, co-ordination, power, reaction time, speed, concentration, determination) (exercise effects)

- explain factors affecting participation and constraints to being active and explore how to overcome the latter in order to gain access to and sustain involvement in activity (activity promotion). (Taken and adapted from Harris, 2000). 
Table 2

607 Example Knowledge and Understanding Outcomes Related to Health Benefits and Activity

608 Promotion

\begin{tabular}{|c|c|c|c|c|}
\hline $\begin{array}{l}\text { Learning } \\
\text { Outcome }\end{array}$ & 5-7 Year Olds & 7-11 Year Olds & 11-14 Year Olds & 14-16 Year Olds \\
\hline $\begin{array}{l}\text { Health } \\
\text { Benefits }\end{array}$ & $\begin{array}{l}\text { explain that } \\
\text { regular activity } \\
\text { improves } \\
\text { health by: } \\
\text {-making you } \\
\text { feel good (e.g. } \\
\text { happy pleased, } \\
\text { content) } \\
\text {-helping body } \\
\text { parts (e.g. } \\
\text { bones and } \\
\text { muscles) to } \\
\text { grow, develop } \\
\text { and work well }\end{array}$ & $\begin{array}{l}\text { explain that } \\
\text { activity } \\
\text { strengthens } \\
\text { bones and } \\
\text { muscles } \\
\text { (including the } \\
\text { heart) and helps } \\
\text { to keep joints } \\
\text { flexible } \\
\text { explain that } \\
\text { activity can help } \\
\text { you to feel good } \\
\text { about yourself } \\
\text { and can be fun } \\
\text { and sociable } \\
\text { maintain a } \\
\text { being active } \\
\text { exps to } \\
\text { explain that } \\
\text { regular activity } \\
\text { permits daily } \\
\text { activities to be } \\
\text { performed more } \\
\text { easily }\end{array}$ & $\begin{array}{l}\text { explain a range of } \\
\text { long-term benefits } \\
\text { of activity on } \\
\text { physical health: } \\
\text {-reduced risk of } \\
\text { chronic disease } \\
\text { (e.g. heart disease) } \\
\text {-reduced risk of } \\
\text { bone disease (e.g. } \\
\text { osteoporosis) } \\
\text {-reduced risk of } \\
\text { some health } \\
\text { conditions (e.g. } \\
\text { obesity, back } \\
\text { pain) } \\
\text {-improved } \\
\text { management of } \\
\text { some health } \\
\text { conditions (e.g. } \\
\text { asthma, diabetes, } \\
\text { arthritis) } \\
\text { and psychological } \\
\text { well-being (e.g. }\end{array}$ & $\begin{array}{l}\text { explain that frequent } \\
\text { and appropriate } \\
\text { activity enhances the } \\
\text { physical, social and } \\
\text { psychological well- } \\
\text { being of all } \\
\text { individuals including } \\
\text { the young and old, } \\
\text { able-bodied and } \\
\text { disabled, and those } \\
\text { with health conditions } \\
\text { (e.g. asthma, } \\
\text { depression) and } \\
\text { chronic disease (e.g. } \\
\text { arthritis) }\end{array}$ \\
\hline
\end{tabular}




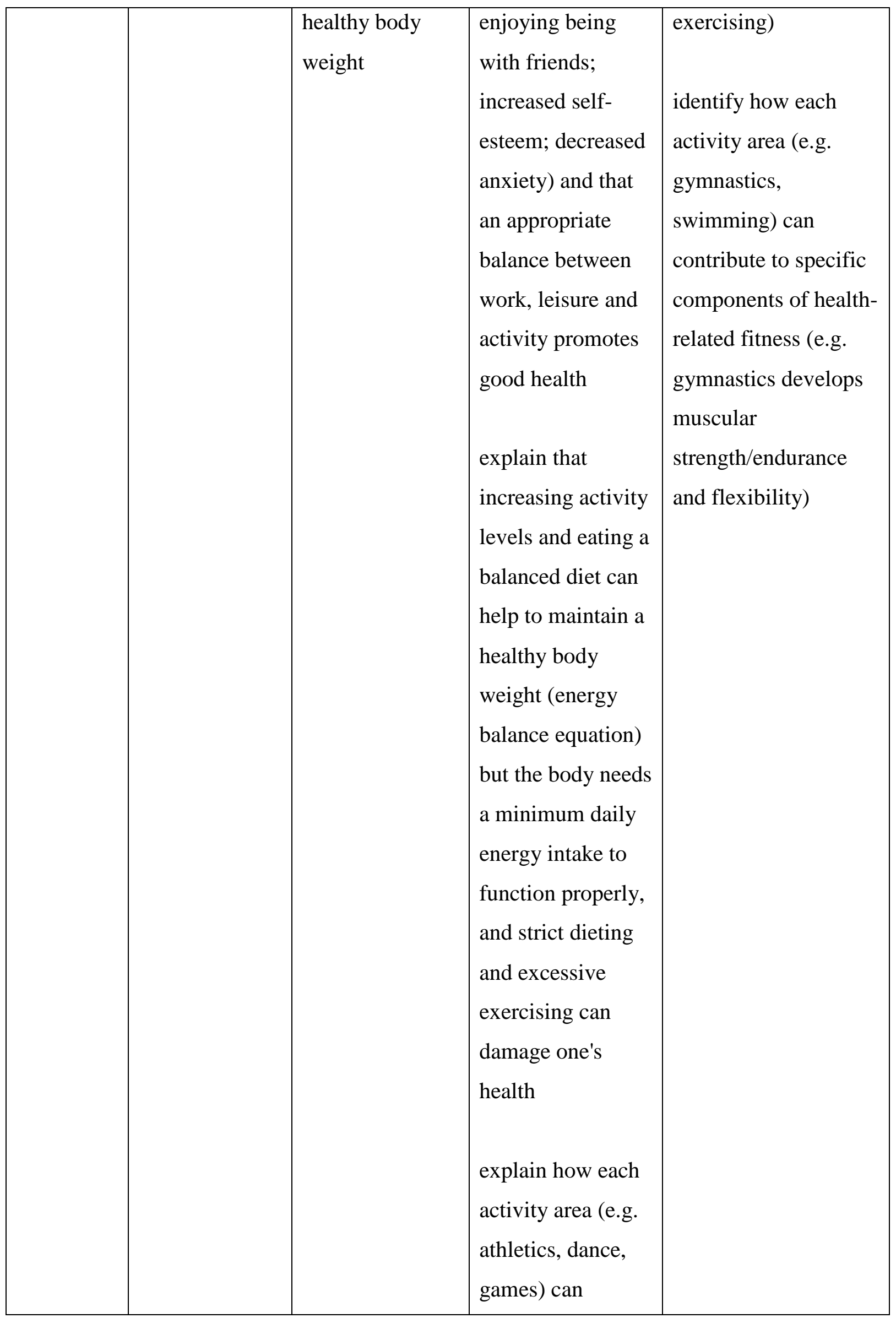




\begin{tabular}{|c|c|c|c|c|}
\hline & & & $\begin{array}{l}\text { contribute to } \\
\text { physical health } \\
\text { and to social and } \\
\text { psychological } \\
\text { well-being (e.g. } \\
\text { can improve } \\
\text { stamina, assist } \\
\text { weight } \\
\text { management, be } \\
\text { enjoyable) }\end{array}$ & \\
\hline $\begin{array}{l}\text { Activity } \\
\text { Promotion }\end{array}$ & $\begin{array}{l}\text { identify when, } \\
\text { where and how } \\
\text { they can be } \\
\text { active at school } \\
\text { (in and out of } \\
\text { lessons) }\end{array}$ & $\begin{array}{l}\text { identify when, } \\
\text { where and how } \\
\text { they can be } \\
\text { active in school } \\
\text { and outside } \\
\text {...explain that } \\
\text { individuals have } \\
\text { different } \\
\text { feelings about } \\
\text { the types and } \\
\text { amounts of } \\
\text { activity that they } \\
\text { choose to do }\end{array}$ & $\begin{array}{l}\text {...know ways of } \\
\text { incorporating } \\
\text { activity into their } \\
\text { lifestyles (e.g. } \\
\text { walking or cycling } \\
\text { to school or to } \\
\text { meet friends; } \\
\text { helping around the } \\
\text { home/garden) } \\
\text {....know how to } \\
\text { go about getting } \\
\text { involved in } \\
\text { activities }\end{array}$ & $\begin{array}{l}\text { explain and } \\
\text { demonstrate a } \\
\text { practical } \\
\text { understanding of the } \\
\text { key principles of } \\
\text { activity programming } \\
\text { and training, } \\
\text { including: } \\
\text {-progression } \\
\text {-overload } \\
\text {-specificity } \\
\text {-balance, moderation } \\
\text { and variety } \\
\text {-maintenance } \\
\text {-reversibility } \\
\text {-cost benefit ratio } \\
\text { explain factors } \\
\text { affecting participation } \\
\text { and constraints to } \\
\text { being active and } \\
\text { explore how to } \\
\text { overcome the latter in }\end{array}$ \\
\hline
\end{tabular}




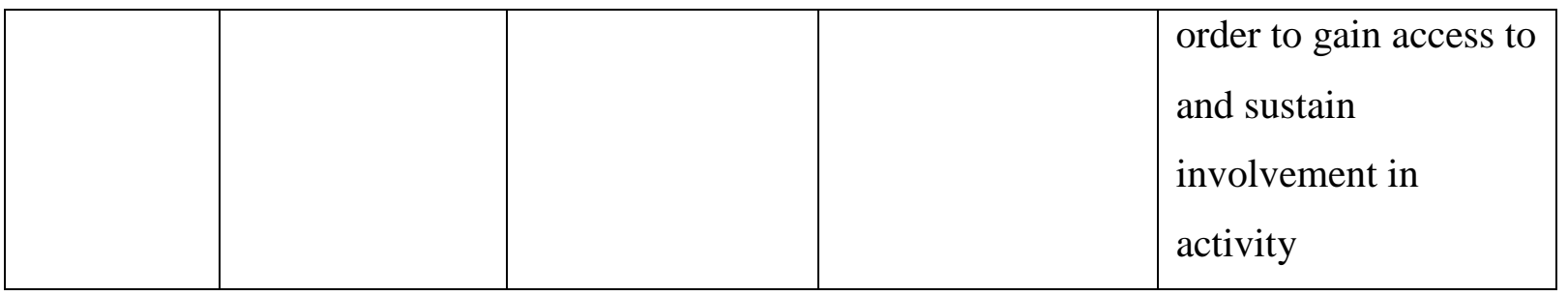

609

610 